\title{
Kim J. Burchiel: Surgical management of pain
}

\section{2nd Edition, Thieme Verlag, New York, Stuttgart, Delhi, Rio, 2015, 652 pp, 189 illustr., Hardcover, EUR (D) 209.99; EUR (A) 215,90; CHF 294,00, ISBN: 978-1-60406-751-4}

\author{
Pierre Kehr ${ }^{1}$
}

Received: 24 July 2015/ Accepted: 25 July 2015/Published online: 21 August 2015

(C) Springer-Verlag France 2015

This vast issue is covered in an exhaustive way in this splendid work, calling upon a large number of specialists to cover all the fields of the treatment of the pain. After an anatomical and physiological recall of the nociceptive and neuropathic pain are treated in detail the practical attitude in front of a painful patient, including the evaluation of the psychological repercussion, the use of opiates, the techniques anesthetic, the importance of the multidisciplinary approach, and finally the chapter of the palliative care.

Nine great chapters are now dedicated to the treatment conservatives of the various pains, of then the lumbagos, the crâniofacial pains, the pains postsurgical, post-traumatic, the cancerous pains.
The surgical treatments are divided into treatments of neuromodulation, like medullary stimulations, stimulations of the peripheral nerves, the nervous destruction. Finally, the new surgical projections are announced.

A rich index allowing a rapid access with the entries and accesses online for videos supplements this richly illustrated work, which will interest not only the neurosurgeons, but all the doctors or surgeons confronted with the assumption of responsibility or the redirection of the painful patients.

Compliance with ethical standards

Conflict of interest None.

Pierre Kehr

pierre.kehr@gmail.com

1 Strasbourg, France 